\title{
Abeilles et cultures oléoprotéagineuses : vers une meilleure compréhension de leurs interactions
}

\author{
Reçu le 2 novembre 2017 - Accepté le 14 novembre 2017
}

Colza et tournesol sont des cultures entomophiles semées chaque année sur près de 2 millions d'hectares en France. Produisant du nectar et du pollen en quantité, elles constituent des ressources substantielles pour les insectes pollinisateurs, au moment même où l'on assiste à un déclin généralisé de leurs populations (Potts et al., 2010; Goulson et al., 2015). Cette ressource massive est de plus à l'origine d'une activité économique, la production de miel, et autres produits de la ruche grâce à l'abeille mellifère.

La relation entre la faune pollinisatrice et les cultures oléoprotéagineuses est par définition bénéfique pour chacune des parties dans la mesure où en collectant nectar et pollen, les insectes participent à la pollinisation. Cependant, la question de savoir dans quelle mesure cette interaction est profitable aux abeilles et aussi à la production grainière reste sujette à débats et fait l'objet de travaux de recherches parfois contradictoires (Kamler et Jas, 2003; Bommarco et al., 2012; Lindström et al., 2015).

Au travers d'études en parcelles expérimentales ou sur des cas territoriaux, les instituts techniques, la recherche publique, les associations de développements apicoles et certaines structures coopératives unissent leurs moyens et leurs compétences pour tenter de répondre à un certain nombre de questions, généralement sur des territoires où la production de miel est devenue difficile. Ainsi, dans ce numéro d'OCL, des thématiques clés seront abordées afin de permettre au lecteur de mieux en appréhender les tenants et aboutissants: (i) la ressource alimentaire produite par les cultures pour les insectes (Chabert et al., 2017 voir aussi Cerrutti et Pontet, 2016); (ii) la contribution de la pollinisation entomophile au rendement du tournesol (Fougeroux et al., 2017); (iii) les déterminants des performances des colonies d'abeilles mellifères (Kretzschmar et Frontero, 2017); (iv) la co-conception de systèmes de cultures favorables à la production agricole et à la production de miel grâce à la concertation territoriale entre apiculteurs et agriculteurs (Gourrat, 2017). Apiculture et agriculture, deux activités de production dépendantes l'une de l'autre ont pourtant des relations mouvementées notamment en raison des pratiques d'épandages des produits phytosanitaires et de leur évolution au cours des trente dernières années (Lagarde, 2017). Sur le modèle de la production de semences hybride qui a compris depuis longtemps la nécessaire collaboration entre apiculteurs et agriculteurs (Conjeaud et Filiol, 2017), il est nécessaire que les deux professions renforcent leur dialogue et prennent en compte leurs intérêts et contraintes respectives.
Loin de toute considération politique ou débat idéologique, certaines interrogations doivent aujourd'hui trouver des réponses pour permettre aux acteurs de remplir leurs objectifs de production tout en enrayant le processus de déclin des insectes pollinisateurs :

- Les insectes polinisateurs naturellement présents dans le milieu sont-ils suffisamment nombreux et diversifiés pour polliniser les cultures oléoprotéagineuses de façon non limitante?

- Quel est le niveau de dépendance réel des cultures oléoprotéagineuses vis-à-vis de l'entomofaune pollinisatrice?

- Les ressources présentes dans l'environnement agricole sont-elles suffisantes et suffisamment réparties dans le temps pour garantir des niveaux de production de miel convenables et permettre le développement des populations d'insectes pollinisateurs?

- Quels sont les facteurs déterminant les performances des colonies d'abeilles mellifères et comment les hiérarchiser?

- Comment concevoir les systèmes de culture pour qu'ils favorisent la faune pollinisatrice tout en maintenant de bons niveaux de production agricole?

Le lecteur trouvera dans ce dossier certains éléments de réponse à ces questions ainsi qu'une vision de la recherche pratiquée à l'étranger (Terzić et al., 2017). Il remarquera que l'abeille mellifère y a une place centrale. Sans doute car elle se trouve à l'interface de deux filières de production. De ce fait, et aussi parce qu'elle est élevée par l'homme donc plus facilement «gérable» que ses consœurs sauvages, elle est devenue un modèle d'étude privilégié et même un indicateur. Ceci ne doit pas faire perdre de vue qu'elle ne représente qu'une espèce parmi les quelques milles espèces d'abeilles présentes sur le territoire national et qui ont des exigences écologiques différentes et des fonctions tout aussi essentielles dans les agro-écosystèmes.

\section{Références}

Bommarco R, Marini L, Vaissière BE. 2012. Insect pollination enhances seed yield, quality, and market value in oilseed rape. Oecologia 169(4): 1025-1032.

Chabert S, Lemoine T, Fronteau L, Vaissière BE. 2017. Mesurer la sécrétion nectarifère : exemple d'une lignée hybride F1 et de son 
parent mâle stérile chez le colza d'hiver (Brassica napus L.). OCL 24(6): D602.

Cerrutti N, Pontet C. 2016. Differential attractiveness of sunflower cultivars to the honeybee Apis melifera L. OCL 32(2): D204.

Conjeaud J-C, Filiol R. 2017. BEEWAPI.com. OCL (24(6): D607.

Fougeroux A, Leylavergne S, Guillemard V, et al. 2017. Effet de l'activité des insectes pollinisateurs sur la pollinisation et le rendement du tournesol de consommation. OCL 24(6): D603.

Goulson D, Nicholls E, Bot C, Rotheray EL. 2015. Bee declines driven by combined stress from parasites, pesticides, and lack of flowers. Science 347: 6229.

Gourrat M. 2017. De la concertation territoriale à l'expérimentation en pleins champs, différents leviers pour accompagner les acteurs d'un territoire agricole à façonner des paysages durablement favorables à des productions oléagineuses et des productions de miel. OCL 24(6): D605.

Kamler F, Jas S. 2003. Influence of pollination by honey bee on seed yield on selected cultivars of winter rape. J Apic Sci 47(2): 119-125.
Kretzschmar A, Frontero L. 2017. Factors of honeybee colony performances on sunflower at apiary level. OCL 24(6): D604.

Lagarde F. 2017. The measures implemented to reduce the impact of plant protection products on pollinators in France. OCL 24(6): D606.

Lindström SA, Herbertsson L, Rundlöf M, Smith HG, Bommarco R. 2015. Large-scale pollination experiment demonstrates the importance of insect pollination in winter oilseed rape. Oecologia 180(3): 759-769.

Potts SG, Biesmeijer JC, Kremen C, Neumann P, Schweiger O, Kunin WE. 2010. Global pollinator declines: trends, impacts and drivers. Trends Ecol Evol 25(6): 345-353.

Terzić S, Miklić V, Čanak P. 2017. Review of 40 years of research carried out in Serbia on sunflower pollination. OCL 24(6): D608.

Nicolas Cerrutti* n.cerrutti@terresinovia.fr 